\title{
Crohn's digestive fistulas, excluding ano-perineal fistulas: about 54 cases
}

\begin{abstract}
Introduction: Crohn's disease is an idiopathic inflammatory enterocolitis characterized by chronic transmural disease that may be associated with or complicated by enterocutaneous (ECF), entero-enteric (EEF), enterovesical (EVF) and rectovaginal fistulae (RVF).

Patients and methods: This is a retrospective study realized over 12 years in the hepatogastroenterology department of the University Hospital of Marrakech including all patients followed for fistulising Crohn's disease outside ano-perineal isolated fistula.

Results: Among the 220 cases of Crohn's disease identified, 54 patients were included at a frequency of $24.5 \%$. There were 29 men and 25 women of 31 years of age \pm 13 years (range: 15 years - 60 years) with a frequency peak between 20 and 40 years. Fistula was inaugural of intestinal disease in $27.4 \%$ of cases $(n=13)$, and complicated the Crohn disease in $72.6 \%$ of patients. Fistule was asymptomatic in $53 \%$ of cases $(\mathrm{n}=29)$ and symptomatic in $47 \%$ of patients $(n=25)$. The frequency according to the type of fistula was as follows: EEF ( 29 cases is $53.7 \%$ ), ECF (19 cases is $35.18 \%$ ), EVF ( 4 cases) and RVF ( 2 cases). Surgical treatment was the rule in $96.87 \%$ of symptomatic patients. All patients had had postoperative medical treatment. Endoscopic recurrence was significantly associated with the type of postoperative medical treatment. It was more common in patients who received aminosalicylates $(71.4 \%)$ compared to those treated with immunosuppressive agents $(20 \%)$ $(\mathrm{P}=0.0008)$. Clinical remission after therapeutic adjustment was noted in $74.3 \%$ of cases, with a median decline of 24 months.
\end{abstract}

Conclusion: Surgical treatment remains indicated in most cases of fistulising Crohn's disease $(70 \%)$. In our study, endoscopic recurrence and clinical remission were significantly associated with the type of postoperative medical treatment.
Volume 9 Issue 2 - 2018

\author{
K Krati, ' A Eyi Nguema,' I El Hidaoui,' S \\ Oubaha, ${ }^{2}$ Z Samlani,' Eyi Nguema Arnaud \\ Georgio' \\ 'Service d'hépato-gastroentérologie, Centre hospitalier \\ universitaire Mohammed VI, Morocco \\ ${ }^{2}$ Département de physiologie, faculté de médecine et de \\ pharmacie, Université Cadi ayyad, Morocco
}

Correspondence: Eyi Nguema Arnaud Georgio, Service d'hépato-gastroentérologie, Centre hospitalier universitaire MohammedVI, Morocco, Email arnaudgeorgio@gmail.com

Received: February 12, 2018| Published: April 19, 2018

Keywords: intestinal fistulas, Crohn's disease

\section{Introduction}

Crohn's disease is an idiopathic inflammatory enterocolitis characterized by chronic transmural disease. This condition can reach any segment of the digestive tract and is usually described with three main phenotypic aspects: inflammatory, stenosing and fistulizing. Described for the first time by Crohn et al. ${ }^{1}$ in 1932, digestive fistulas can accompany or complicate Crohn's disease in 20 to $40 \%$ of cases. ${ }^{1}$ They include external fistula (enterocutaneous (FEC) and anoperineal fistula) and internal fistula (enteroenteral (FEE), enterovetic (FEV) and rectovaginal (LIF)). These lesions are the most easily diagnosed whether they are symptomatic or not, and are responsible for significant morbidity. Before the introduction of biotherapies, most fistulas were treated by surgery, with a recurrence rate estimated at $34 \% .^{2-4}$ The aim of our work is to study the epidemiological, clinical, radiological, therapeutic and evolutionary aspects of intestinal fistulas, apart from anoperineal fistulas, during Crohn's disease and to highlight the difficulties of management of these patients.

\section{Patients and method}

This is a retrospective descriptive study conducted in the hepatogastroenterology department of the Mohammed VI University Hospital in Marrakech between January 2004 and July 2016. Using the hospitalization registers, all cases of Crohn's disease (diagnosis retained on a bundle of clinical, biological, morphological and histological arguments) were reviewed. We included patients with intestinal Crohn's disease with fistulizing phenotype, apart from isolated anoperineal fistulas. The parameters studied were age, sex, antecedents, duration of illness, location of the disease, type of fistula, localization of fistulas, clinical examination data, imaging and endoscopy, medical and surgical treatment, evolution and followup. Statistical analysis was performed using SPSS 10.0 software. Quantitative variables are expressed in medians and extremes and qualitative values are expressed as a percentage. The comparison of the qualitative variables is carried out using the Fisher or Khi Deux exact test. The significance level was $\mathrm{p}<0.05$.

\section{Results}

During the study period, 220 cases of Crohn's disease were identified, 54 patients had an intestinal fistula at a frequency of $24.5 \%$. There were 29 men and 25 women with a sex ratio of 1.16 . The mean age was 31 years \pm 13 years (range: 15 years - 60 years) with a peak frequency between 20 and 40 years (more than $70 \%$ of cases) (Figure 1). An appendectomy preceded the appearance of fistula in 19 patients. There was active smoking in 18 patients. Three patients had a family history of IBD. At the time of diagnosis, the average duration of disease progression was 80 months (range: 1 to 160 months); and in 22 patients the fistula had been evolving for more than 1 year. Intestinal disease was colonic ( $2 \%$ of cases) ileal ( $13 \%$ of cases) and ileocolic ( $85 \%$ of cases). Six patients (11.1\% of cases) had associated LAPs. 
Fistula was inaugural for intestinal disease in $27.4 \%$ of cases $(n=13)$, and complicated the disease in $72.6 \%$ of cases. Fistula was incidental discovery in $53 \%$ of cases $(n=29)$ respectively postoperatively $(n=17)$, imaging $(n=7)$ and per endoscopy $(n=5)$, and symptomatic in $47 \%$ of patients $(n=25)$. They were symptomatic in all cases $(n=19)$ of FEC in the form of percutaneous discharge of pus or faeces. FEVs were symptomatic in $75 \%$ of cases $(n=3)$ in the form of pneumaturia and / or faecaluria. Abdominal pain predominating in the right iliac fossa revealed FEE in five patients. LIFs were symptomatic in one out of two cases with feces or air from the vagina, and were associated with ano-perineal fistulas in both cases. The clinical examination showed, in the case of FEE, an impaction of the right iliac fossa in $11.9 \%$ of patients $(n=7)$. In CEF, abdominal examination revealed one or more fistulous openings, with $75 \%$ of the cases located in the right iliac fossa (Figure 2). The vaginal touch allowed the perception of the internal fistular orifice in 1 case of FRV. Fistulas were visualized by various radiological and endoscopic examinations. The FEEs were mainly objectified by CT enteroclysis in $100 \%$ of cases (performed in 3 patients), by the passage of hail in $60 \%$ of cases $(n=20)$ associated with ileal stenosis downstream in all cases; and abdominal ultrasound in $13 \%$ of cases. Colonoscopy revealed fistulous openings for enteroenteral fistulas in three patients. The CTF were objectified by CT enteroclysis in $100 \%$ of cases (performed in 5 patients) by the passage of the small intestine in $66 \%$ of cases (18), associated with ileal stenosis downstream in $50 \%$ of cases; and by abdominal ultrasonography in $61 \%$ of cases (18), associated with intra-abdominal abscess in $90 \%$ of cases. Fistulography was performed in only one case of FEC. The FEV had been objectified by urography in $100 \%$ of cases (performed in 2 patients), by bladder ultrasound in $57 \%$ of cases (7) showing intravesical air bubbles, by cystoscopy (showing an orifice fistulous), retrograde cystography and hail transit in one case respectively. The barium enema was performed in a LIF case. Figure 3 summarizes the distribution according to the topography. Therapeutically, only symptomatic fistulas had been treated. Enteroenteral fistulas benefited in $100 \%$ of cases from surgical treatment preceded by abscess forms (11.9\% of cases) of antibiotic therapy and parenteral nutrition with drainage; all cases of enterocutaneous fistulas $(22.6 \%$ of cases) had dual antibiotic treatment with ciprofloxacin (1g/24h) and metronidazole $(1.5 \mathrm{~g} / 24 \mathrm{~h})$ prior to surgical treatment; all patients with enterovasal fistula $(7.1 \%$ of cases) had a limited resection of the fistulized intestinal segment with bladder breccia blindness and urinary catheterization for 10 days in all cases. A patient with a rectovaginal fistula had been surgically treated by resection of the fistulous tract associated with a suture of the residual orifice on the rectum and interposition of the vaginal wall, the other asymptomatic patient (presenting a combination of rectovaginal and anoperineal fistulas) a been put on anti-TNF (Infliximab). Therapeutic indications for different types of fistulas are summarized in Table 1. Most operated patients had limited resection $(72.7 \%)$, whereas extensive resection was performed in $27.3 \%$ of patients. The maintenance TTT was prescribed in all patients: Anti TNF alpha (11.1\% of cases), thiopurines in $66.7 \%$ of patients and aminosalicylates in $22 \%$ of cases. Regarding asymptomatic fistulas (57\% of cases): when they were discovered intraoperatively for surgery for stenosis ( $27.4 \%$ of cases), the fistulous pathway was carried away in the resected segment. In the event of a radiological (26.19\% of cases) or endoscopic $(18.5 \%$ of cases) finding, therapeutic abstention was chosen. The main immediate postoperative complications were: suture release $(2.38 \%$
( 2 cases), evisceration: $2.38 \%$ ( 1 case), flanged occlusion ( 1 case), one death was due to severe pneumonia. In the long term, the progression was marked by the absence of recurrence in $94.5 \%$ of patients with an average follow-up of 56 months. The recurrence occurred in three patients: 2 cases of enterocutaneous fistulas and 1 case. The two patients who had recurrence of enterocutaneous fistula had been reoperated and put on azathioprine with clinical remission. The patient with recurrent rectovaginal fistula was put on anti-TNF with good evolution. postoperative colonoscopy was performed in $64.8 \%$ of cases $(n=35)$ between the 6 th and 12 th postoperative months with a median of 8 months, was normal in 17 cases, and endoscopic lesions in 18 cases Endoscopic recurrence was significantly associated with the type of postoperative medical treatment. It was more common in patients who received aminosalicylates $(71.4 \%)$ compared to those treated with immunosuppressive agents $(20 \%)(\mathrm{P}=0.0008)$. Clinical remission after therapeutic adjustment was noted in $74.3 \%$ of cases, with a median of decline of 24 months.

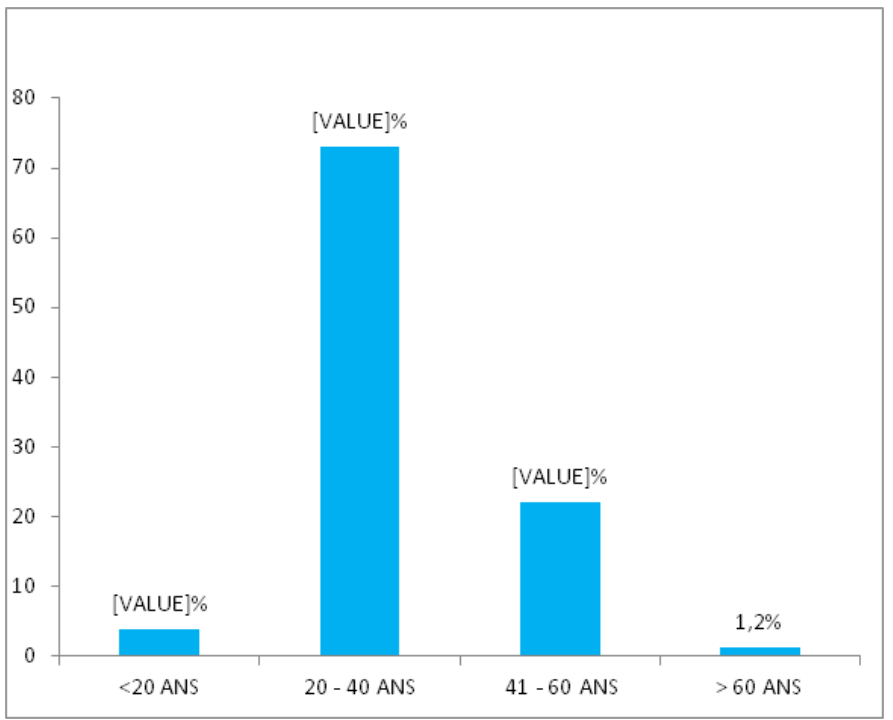

Figure I Age distribution of patients.

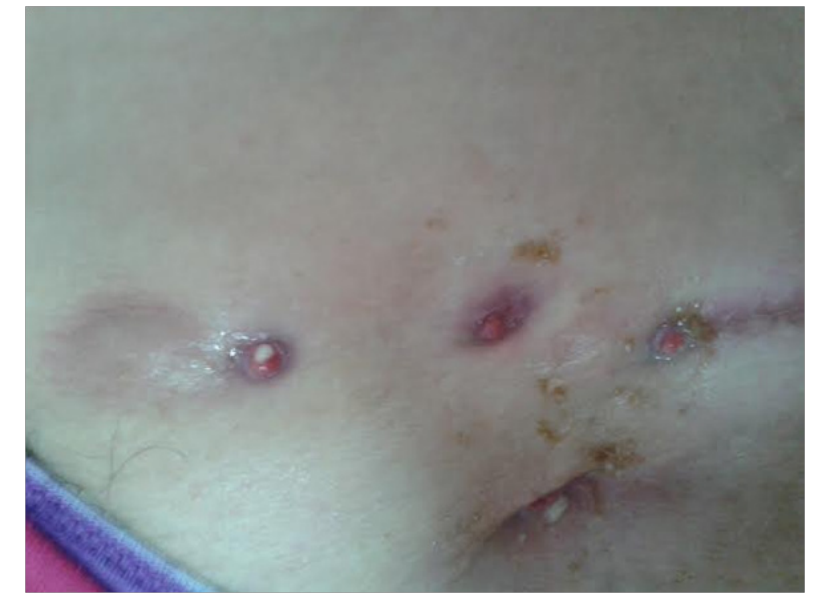

Figure 2 Multiple external cutaneous fistula holes in a patient with Crohn's disease. 


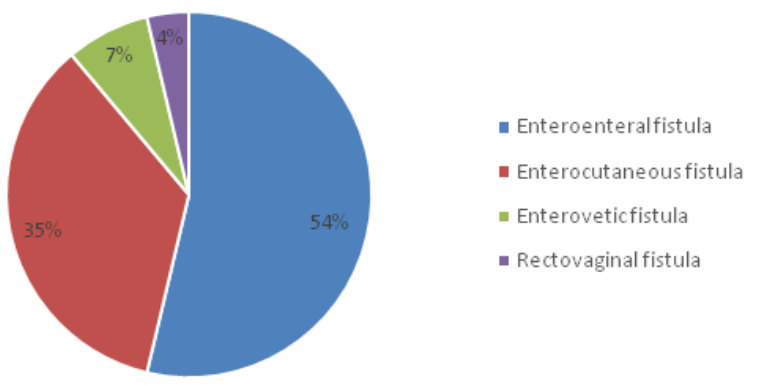

Figure 3 Distribution according to the location of the fistula.

Table I Indications of treatment according to the type of fistula

\begin{tabular}{lcll}
\hline Type of fistula & $\mathbf{n}$ & Medical treatment & $\begin{array}{l}\text { Surgical } \\
\text { treatment }\end{array}$ \\
\hline Enteroenteral fistula & 29 & $\begin{array}{l}\text { 7- continuation or } \\
\text { modification of the } \\
\text { background treatment }\end{array}$ & 22 \\
$\begin{array}{l}\text { Enterocutaneous } \\
\text { fistula }\end{array}$ & 19 & 19-Antibiotics & 19 \\
Enterovetic fistula & 4 & & 4 \\
Rectovaginal fistula & 2 & I- Infliximab & I \\
\hline
\end{tabular}

\section{Discussion}

Crohn's disease is a multifactorial inflammatory bowel disease characterized by chronic transmural disease. This transmural nature of inflammation predisposes patients to fistula formation. In our study, $24.5 \%$ of patients with Crohn's disease had developed an intestinal fistula and most of them had ileocolic localization. The incidence of fistulas in patients with CD varies from 17 to $43 \%$ depending on the series. ${ }^{5}$ It is $35 \%$ all fistulas combined in the study by Schwartz et al. ${ }^{2}$ In this population study based on the natural history of fistula in CD, which included 176 patients diagnosed between 1970 and 1993, the authors found a cumulative incidence of $21 \%$ at 1 year, $26 \%$ at 5 years, $33 \%$ at 10 years and $50 \%$ to 20 years. FEE (24\% of cases) came second after anoperineal fistulas. This study highlights that the incidence of intestinal fistulas increases with the duration of the disease. This evolution appears to be related to phenotypic change, intestinal involvement and age at diagnosis. Indeed, Cosnes et al. ${ }^{6}$ in a retrospective study based on the natural history of intestinal fistula in Crohn's disease, including 200 patients, showed that the intestinal localization was associated with an evolution towards the fistulising type, and that one-third of patients with an inflammatory phenotype at diagnosis may progress to these forms. Louis et al. ${ }^{7}$ in a retrospective study of 300 patients with Crohn's disease and followed for 25 years showed that there was a change in the phenotypic profile during evolution, although the localization of the disease remained stable. In fact, in this study, $50 \%$ of patients had a change in phenotype of their disease after 10 years of evolution, and $30 \%$ of patients with inflammatory phenotype at the time of diagnosis of chronic disease expressed a fistulising form after 10 years. 'evolution. This study also showed that patients with ileocolic or colic involvement (as in our series) were more likely to have penetrating forms than those with strict ileal involvement. Thus, the risk of developing digestive fistula in Crohn's disease was significantly higher in ileal than in pure colic. ${ }^{8}$

Diagnosis of intestinal fistulas is usually easy when they are symptomatic, assisted by imaging in all cases. The symptomatology differs according to the location. FEE are most often asymptomatic or manifest as non-specific symptoms. ${ }^{9}$ Entero-cutaneous fistulas are responsible for fecal discharge through the fistular opening which can be single or multiple, at high or low flow, depending on the complexity of the fistulous tract, the intestinal segment reached and the presence or no downstream stenosis. ${ }^{10,11}$ The diagnosis of entero-vesical fistulas is most often clinical. They are responsible for recurrent urinary tract infections, fecaluria, pneumaturia or dysuria. ${ }^{12,13}$ Rectovaginal fistulas are rarer. Their incidence is probably proportional to the severity of inflammatory colitis and the presence of anoperineal manifestations. ${ }^{14}$ Clinical signs usually include a vaginal discharge of gas or feces, dyspareunia, vaginal irritation, and recurrent genitourinary infections. ${ }^{15,16}$ Several radiological examinations may contribute to the diagnosis of fistulas of Crohn's disease. These include the passage of the small intestine, the barium enema, and fistulography, which are now completely supplanted by sectional imaging techniques, namely abdominal ultrasound, CT enteroclysis, entero-MRI. ${ }^{17}$ In our study, only symptomatic fistulas were treated. Surgery was the treatment of choice in the majority of cases. Indeed, the treatment of intestinal fistulas remains surgical in more than $95 \%$ of cases. In case of asymptomatic fistula, no treatment is necessary. ${ }^{17}$ Surgical treatment is indicated in cases of symptomatic FEE, especially in case of diarrhea and/or malabsorption due to the anatomical short circuit created by the fistula or in case of occurrence of a deep abscess. ${ }^{18}$ In the series of Michelassi et al. ${ }^{19}$ the operative indication in enteroenteral fistulas was brought first to the failure of medical treatment (35\%), then to Koenig's syndrome (29\%) and finally directly for fistula itself (18\%). In case of enterovascular or rectovaginal fistula, the resection of the pathological intestinal segment remains the best therapeutic option, unless there is a risk of short hail or definitive stoma. ${ }^{18} \mathrm{~A}$ small sample series ${ }^{20-22}$ evaluated the efficacy of thiopurines as first-line treatment: improvement in symptomatology was noted in patients with FEV or LIF. In fact, according to Nielsen et al. ${ }^{22}$ thiopurines can be used as second-line therapy in patients with fistulising Crohn's disease if surgery is not urgent. An analysis of the ACCENT II cohort data revealed a beneficial effect of infliximab on rectovaginal fistulas with a fistula closure rate of $60.7 \%$ and $44.8 \%$ at week 10 and 14 , respectively. ${ }^{23}$

In the case of enterocutaneous fistulas, surgical treatment is the rule in the majority of cases. In a study involving 51 patients who received surgical treatment for entero-cutaneous fistulas on Crohn's disease, Poritz et al. ${ }^{24}$ reported a surgical closure rate of $84 \%$ with a mean follow-up of 48 months. The recidivism rate was $16 \%$. In our study, the surgical closure rate of fistulas was $96 \%$ and the fistula recurrence rate was $4 \%$. However, work done by GETAID evaluated the efficacy of anti-TNF in 51 patients with Crohn's disease on enterocutaneous fistulas treated with anti-TNF. ${ }^{25,26}$ A complete closure of the fistula was obtained in a third of patients with a sustained response (medical follow-up 56 months on average) observed in half of them, to consider anti-TNF treatment in this situation until recently essentially surgical. In our study, all patients received post-operative medical treatment predominantly immunosuppressive, and all three patients with recurrence at 1 year were predominantly aminosalicylated. A recent study compared azathioprine with mesalazine in 78 patients operated on for Crohn's disease. Clinical recurrence at one year was 
more frequent in the mesalazine group than in the azathioprine group $(10.8 \%$ versus $0 \%)$ and the rate of endoscopic improvement of more than one point on the Rutgeerts score was significantly higher. frequent with azathioprine $(63.3 \%$ versus $34.4 \%) .{ }^{27}$ Post-surgery management is decided at 15 days of the surgical procedure and depends on the presence, or not, of the risk factors for recurrence: active smoking, history of intestinal resection for Crohn's disease, fistulising phenotype (B3 according to the classification of Montreal), intestinal resection length $(>50 \mathrm{~cm})$. It is recommended that immunosuppressive therapy and/orTNF alpha antagonist be initiated in the presence of at least one risk factor. ${ }^{10,28}$

\section{Conclusion}

Crohn's fistulas are common in our context. They are dominated by enteroenteral forms. Their diagnosis is easy especially when they are symptomatic and often helped by the imagery that allows to describe the associated lesions. Surgical treatment is the rule in most symptomatic situations. But in some cases, anti-TNF alpha has proved effective. This involves consultation between gastroenterologists, surgeons, radiologists and anatomo-pathologists to decide on the best therapeutic option for each patient. Finally, these complications are a source of significant morbidity requiring psychological support of patients.

\section{References}

1. Crohn BB, Ginzburg L, Oppenheimer GD. Regional ileitis: a pathologic and clinical entity. JAMA. 1932;99(16):1323-1329.

2. Schwartz DA, Loftus EV Jr, Tremaine WJ, et al. The natural history of fistulizing Crohn's disease in Olmsted County, Minnesota. Gastroenterology. 2002;122(4):875-880.

3. Hellers G. Crohn's disease in Stockholm county 1955-1974. A study of epidemiology, results of surgical treatment and long-term prognosis. Acta Chir Scand Suppl. 1979;490:1-84.

4. Agrez MV, Valente RM, Pierce W, et al. Surgical history of Crohn's disease in a well-defined population. Mayo Clin Proc. 1982;57(12):747752 .

5. Mark T Osterman, Gary R Lichtenstein. Infliximab in fistulizing crohn's desease. Gastroenterol Clin N Am. 2006;35(4):785-820.

6. Cosnes J, Cattan S, Blain A, et al. Long-term evolution of disease behavior of Crohn's disease. InflammBowel Dis. 2002;8(4):244-250.

7. Louis E, Collard A, Oger A, et al. Behaviour of Crohn's disease according to the Vienna classification: changing pattern over the course of the disease. Gut. 2001;49(6):777-782.

8. Thia KT, Sandborn WJ, Harmsen WS, et al. Risk factors associated with progression to intestinal complications of Crohn's disease in a populationbased cohort. Gastroenterology. 2010;139(4):1147-1155.

9. Bouhnik Y, Panis Y. Prise en charge médico-chirurgicale de la maladie de crohn fistulisante: traitement médical ou chirurgie. Gastroenterol Clin Biol. 2003;27(Suppl 3):S98-103.

10. Hawker P, Givel JC, Keighley MR, et al. Management of enterocutaneous fistulae in Crohn's disease. Gut. 1983;24(4):284-287.
11. Kirsh GM, Hampel N, Shuck JM, et al. Diagnosis and management of vesicoenteric fistulas. Surg Gynecol Obstet. 1991;173(2): 91-97.

12. Solem CA, Loftus EV, Tremaine WJ, et al. Fistulas to the urinary system in Crohn's disease: clinical features and outcomes. Am J Gastroenterol. 2002;97(9): 2300-2305.

13. Andreani SM, Dang HH, Grondona $\mathrm{P}$, et al. Rectovaginal fistula in Crohn's disease. Dis Colon Rectum. 2007;50(12):2215-2222.

14. Casadesus D, Villasana L, Sanchez IM, et al. Treatment of rectovaginal fistula: a 5-year review. Aust N Z J Obstet Gynecol. 2006;46(1):49-51.

15. Ruffolo C, Penninckx F, Van Assche G, et al. Outcome of surgery for rectovaginal fistula due to Crohn's disease. Br J Surg. 2009 ;96(10):11901195.

16. Michelassi F, Stella M, Balestracci T, et al. Incidence, diagnosis and treatment of enteric and colorectal fistulae in patients with Crohn's disease. Ann Surg. 1993;218(5):660-666.

17. Pariente B, Bouhnik Y. Maladie de Crohn du grêle. POST'U. 2011. p.115-124.

18. Gert Van A. The second European evidence-based Consensus on the diagnosis and management of Crohn's disease: Special situations. $J$ Crohns Colitis. 2010;4(1):63-101.

19. Margolin ML, Korelitz BI. Management of bladder fistula in Crohn's disease. J Clin Gastroenterol. 1989;11(4):399-402.

20. Glass RE, Ritchie JK, Lennard-Jones JE, et al. Internal fistulas in Crohn's disease. Dis Colon Rectum. 1985;28(8):557-561.

21. O'Brien JJ, Bayless TM, Bayless JA. Use of azathioprine or 6-mercaptopurine in the treatment of Crohn's disease. Gastroenterology. 1991;101(1):39-46.

22. Nielsen $\mathrm{OH}$, Rogler G, Hahnloser D, et al. Diagnosis and management of fistulizing Crohn's disease. Nat Clin Pract Gastroenterol Hepatol. 2009;6(2):92-106.

23. Sands BE, Blank MA, Patel K, et al. Long-term treatment of rectovaginal fistulas in Crohn's disease: response to infliximab in the ACCENT II Study. Clin Gastroenterol Hepatol. 2004;2(10):912-920.

24. Poritz LS, Gagliano GA, Mcleod RS, et al. Surgical management of entero and colocutaneous fistulae in Crohn's disease: 17 years experience. Int $J$ Colorectal Dis. 2004;19(5):481-485.

25. Setakhr V, Seksik P, Treton X, et al. Efficacité des anticorps anti-TNF dans le traitement des fistules entéro-cutanées compliquant la maladie de Crohn.

26. Sands BE, Anderson $\mathrm{FH}$, Bernstein $\mathrm{CN}$, et al. Infliximab maintenance therapy for fistulizing Crohn's disease. N Engl J Med. 2004;350(9):876885 .

27. Reinisch W, Angelberger S, Petritsch W, et al. Azathioprine versus mesalazine for prevention of postoperative clinical recurrence in patients with Crohn's disease with endoscopic recurrence: efficacy and safety results of a randomized, double blind, double-dummy, multicentre trial. Gut. 2010;59(6):752-759.

28. Peyrin-Biroulet L, Bouhnik Y, Roblin X, et al. Algorithmes de prise en charge de la maladie de Crohn en 2016 : consensus national francais. Hepato Gastro. 2016;23(7):619-633. 